\title{
Preinfestations of tomato plants by whiteflies (Bemisia tabaci) or aphids (Macrosiphum euphorbiae) induce variable resistance or susceptibility responses
}

\author{
G. Nombela ${ }^{1 \dagger}$, E. Garzo $^{1 \dagger}$, M. Duque ${ }^{2}$ and M. Muñiz ${ }^{1 *}$ \\ ${ }^{1}$ Departamento de Protección Vegetal, Instituto de Ciencias Agrarias, \\ Centro de Ciencias Medioambientales, Consejo Superior \\ de Investigaciones Científicas, Madrid 28006, Spain: ${ }^{2}$ Instituto de Biología \\ y Genética Molecular, CSIC, Valladolid 47003, Spain
}

\begin{abstract}
In addition to constitutive plant resistance against pests or pathogens, plants can activate protective mechanisms upon contact with an invader or a chemical elicitor. Studies on induced plant resistance to herbivores, especially piercingsucking insects, are less abundant than those devoted to pathogens. Several experiments under controlled conditions have been conducted to demonstrate that infestations by Macrosiphum euphorbiae induce plant resistance to Bemisia tabaci in susceptible tomato plants. After three days of exposure to 20 apterous adult aphids, the plants acquired a transiently induced resistance to $B$. tabaci when aphid removal occurred one or 18 hours prior to $B$. tabaci infestation; the effect disappeared when four days passed between aphid and whitefly infestations. The resistance observed was both locally and systemically induced. Other assays were performed to evaluate the effect of preinfestation with ten adults of $B$. tabaci during $48 \mathrm{~h}$ on the tomato responses to two different clones ( $\mathrm{Sp}$ and $\mathrm{Nt}$ ) of M. euphorbiae. The numbers of nymph and adult aphids were counted after the same time interval as the pre-reproductive period and 20 (Sp clone) or 22 (Nt clone) days after adult aphid removal. The tomato responses induced by whitefly feeding depend on the aphid clone. For the Sp clone, the number of aphid nymphs ten days after adult removal was significantly higher on whitefly preinfested plants than on uninfested plants. However, no significant differences were observed when the aphid clone $\mathrm{Nt}$ was tested. The duration of plant response to a previous infestation by $B$. tabaci is apparently limited.
\end{abstract}

Keywords: aphids, Bemisia tabaci, induced resistance, LAR, Macrosiphum euphorbiae, SAR, Lycopersicon esculentum, tomato, whiteflies

(Accepted 24 May 2008)

*Author for correspondence

Fax: + 1(34) 915640800

E-mail: mmuniz@ccma.csic.es

$\dagger$ These authors contributed equally to this work.

\section{Introduction}

Plant resistance to pests and diseases often occurs as the expression of a variety of innate or constitutive defence systems, triggered by the presence of certain plant resistance (R) genes. For instance, the cloned gene $\mathrm{Mi}-1$ confers resistance to many tomato Lycopersicon esculentum cultivars against the three most common and damaging species of root-knot 
nematodes, Meloidogyne incognita, M. javanica and M. arenaria (Roberts \& Thomason, 1986); the potato aphid Macrosiphum euphorbiae (Rossi et al., 1998); and the B and Q biotypes of the main whitefly vector of plant viruses, Bemisia tabaci (Nombela et al., 2003).

In addition to this constitutive resistance, plants can activate protective mechanisms against a pest or pathogen upon contact with a previous invader. This is termed induced or acquired resistance, and it can be systemically expressed (systemic acquired resistance, or SAR, and induced systemic resistance, or ISR) or confined only to previously infested plant parts (local acquired resistance, or LAR). Although there is wide variation in the terminology, it is currently agreed by a good part of the research community that induced resistance is the general term by which all types of elicited responses that lead to enhanced protection against disease can be designated (Hammerschmidt et al., 2001). In addition, this term is used to denote reduced plant damage by herbivorous insects after a previous attack, when plantinsect interactions are considered (Hammerschmidt et al., 2001). Some biological agents, such as certain bacteria, fungi or viruses, can induce plant resistance to other pathogens (Agrawal et al., 1999; Hammerschmidt et al., 2001; Siddiqui \& Shaukat, 2004). Similarly, positive and negative associations as a result of cross-talk between insect- and pathogeninduced defence pathways have been widely reported (reviewed by Hunter, 2000), including the induction of plant resistance to insects due to a previous attack by the same or another organism. More specifically, over 100 plant species have been found to respond to past or current herbivory by increasing their resistance to herbivores (Karban \& Baldwin, 1997). In these interactions, the initial attack acts as a cue to predict a risk of future herbivory for the plant, which changes its defensive phenotype to produce reduced fitness and/or preference of insect feeding (Karban et al., 1999). On the contrary, there may also be opposing effects induced by a previous infestation, making the plant more attractive and/ or susceptible to other herbivores (Prado \& Tjallingii, 1997; Thaler et al., 2001).

There are results to support that induced resistance could be attributable to changes in the emission of volatile compounds by plants previously infested by insects. Infestation of cotton by leaf chewing beet armyworm, Spodoptera exigua, strongly induced plant volatile emission, whereas infestation with whitefly B. tabaci (B-biotype) did not induce volatile emissions (Rodríguez-Saona et al., 2003). Whereas many of these compounds attract natural enemies of the herbivores responsible for the damage, other plant volatiles are known to elicit priming mechanisms which deter insects directly (reviewed by Hunter, 2002; Engelberth et al., 2004; Heil \& Kost, 2006).

Available information on induced resistance to arthropods mostly refers to chewing herbivores, which usually cause extensive leaf damage to infested plants. A less studied phenomenon is the induction of plant resistance to/by phloem-feeding insects, such as whiteflies or aphids, which maintain a longer interaction with their host plant but cause only limited direct damage to the plant tissues with their stylets (Walling, 2000). Most reports on phloem-feeding insects have focused on induced responses (positive or negative) to aphids, acquired by the plant upon a previous infestation by the same or another aphid species (Wool \& Hales, 1996; Quiroz et al., 1997; Messina et al., 2002; Sauge et al., 2002), among other biotic or abiotic inducers. However, little is known to date about plant responses to whiteflies induced after previous attacks by arthropods or by other inducer factors (Inbar et al., 1999; Agrawal et al., 2000; Mayer et al., 2002; Murugan et al., 2006). In a recent study from our laboratory, it was reported that treatment with Benzothiadiazole (BTH), which mimics the biological activation of SAR by necrogenic pathogens (Kunz et al., 1997) and induces resistance in different cultivated plants against a broad spectrum of fungal, bacterial and viral diseases (Oostendorp et al., 2001; Smith-Becker et al., 2003), also induced local resistance in tomato to both B and Q biotypes of B. tabaci (Nombela et al., 2005). Previously, it was demonstrated that BTH induced resistance in tomato to $M$. euphorbiae (Cooper et al., 2004), which suggests the possible existence of overlap between plant defences against these two insect pests.

Several bioassays were carried out under controlled conditions in the present work to test if resistance to whitefly $B$. tabaci could be induced in susceptible tomato plants (lacking the $M i-1$ gene) by a previous infestation with the potato aphid M. euphorbiae. Moreover, the question whether the induced response to $B$. tabaci would be local or systemically expressed in other parts of the plant was also addressed. Conversely, other assays were performed to evaluate the effect of a preinfestation with $B$. tabaci on the tomato responses to two different aphid clones of $M$. euphorbiae.

\section{Materials and methods}

\section{Plant material}

Tomato plants (L. esculentum cv. Marmande) were used in this study. Marmande plants lack the Mi-1 gene which is responsible for innate resistance to both $B$. tabaci and M. euphorbiae, so this cultivar is highly susceptible to these insect pests. Tomato seeds were germinated in a climatic chamber maintained at a day: night temperature regime of $26: 20^{\circ} \mathrm{C}$ and a photoperiod of $16: 8 \mathrm{~h} \mathrm{~L}: \mathrm{D}$. Plants were grown in vermiculite in one-litre plastic pots irrigated every ten days with a $3 \mathrm{grl}^{-1}$ solution of the nutritive complex 2020-20 (Nutrichem 60; Miller Chemical, Hanover, PA, USA) and with tap water when needed in the meantime. Onemonth-old plants were used in all assays and, at this stage, plants had six or seven fully expanded true leaves.

\section{Insect populations}

Adult female whiteflies (B-biotype of B. tabaci) were used in this study. A population had been initially obtained from cucumber plants and, after several years, it was transferred to tomato $\mathrm{cv}$. Marmande where it has been reared for more than 50 generations.

A potato aphid clone (M. euphorbiae) was established from a single virginoparous aptera female collected in 1999 on lettuce in Villa del Prado, Madrid (Sp clone). The colony was reared on tomato plants $\mathrm{cv}$. Marmande kept in cages at a day:night temperature of $22: 16^{\circ} \mathrm{C}$ and a photoperiod of $14: 10 \mathrm{~h}$ L:D. A second aphid clone (Nt clone) was obtained from potato plants in The Netherlands and reared on tomato cv. Marmande for six months. Only young adult aphids, one- to three-days old, were used for infesting tomato plants.

\section{Tomato response to whiteflies: preinfestations with aphids}

Three no-choice assays were performed in a growth chamber at a constant temperature of $24^{\circ} \mathrm{C}$, a photoperiod of 
$16: 8 \mathrm{~h} \mathrm{~L}: \mathrm{D}$ and a relative humidity of $68-75 \%$. For the first and second assay, each of ten tomato plants was infested with 20 apterous adult aphids confined in a transparent plastic cage $(6.5 \times 2 \mathrm{~cm})$ attached to a leaf in a similar way as described by Fereres et al. (1989). The leaf used was the upper-most fully expanded leaf of every plant. Another ten plants without aphids or cages were used as control. In addition, cages with no aphids were placed on four other plants of the first assay to test for the possible influence of the plastic cages on plant response. Aphids where kept on the plants for three days, and then adult aphids and laid nymphs were gently removed using a soft little brush. No dead aphids were observed on the plants. Plants of the first and second assays were maintained in the growth chamber for one hour or four days, respectively, until whitefly infestation.

A third assay was carried out under similar conditions but, in this case, 15 plants were infested for three days with 20 adults of $M$. euphorbiae in one leaf as previously described; and 15 other non-infested plants with empty cages were used as control. For this assay, $18 \mathrm{~h}$ passed between aphid removal and whitefly infestation.

\section{Tomato response to whiteflies: whitefly infestations}

Every preinfested or control plant from the first and second assays was covered with a transparent plastic cylinder $(27 \mathrm{~cm}$ high, $12 \mathrm{~cm}$ diameter) with a thin polypropylene insect mesh attached by paraffin wax to the top and two other holes on the cylinder surface to allow ventilation. Five adult female whiteflies were released on the tomato plant inside the cylinder through another hole sealed with a small cork. For both assays, whiteflies were kept on the plants for 27 days, and then the numbers of third (L3) and fourth-stage (L4) nymphs and adult whiteflies on every plant were recorded. The number of adults was deduced from the observed number of empty pupal cases.

In the third assay (18 h after aphid removal), five adult female whiteflies were confined to a plastic truncated cone clip-cage $(3.6 \mathrm{~cm} \times 2.6 \mathrm{~cm}$ diameter; $4 \mathrm{~cm}$ high) (Muñiz \& Nombela, 2001). The clip-cage was attached to the same previously caged leaf of every aphid-infested or control plant, such that whiteflies had access only to the abaxial surface of the leaf. In addition, to test if plant resistance was systemically acquired (SAR), another similar clip-cage with five whiteflies was attached to the contiguous upper leaf of every plant. Five days later all female whiteflies and clip-cages were removed from the plants, and the corresponding leaflets were marked with small paper rings attached to their petioles. Eggs were allowed to develop for 22 more days, and then the numbers of L3, L4 and adult whiteflies were counted as detailed for the other assays.

Data from aphid-infested and control plants or from infested and uninfested leaves were $\log _{10}(x+1)$ transformed and analyzed by a one-way ANOVA and means compared by the Tukey HSD test (Statgraphics, 1997).

\section{Tomato response to aphids: preinfestations with whiteflies}

Two no-choice assays were performed in a growth chamber under conditions similar to those previously used for the study of the tomato responses to whiteflies. Every tomato plant was covered by a transparent plastic cylinder $(27 \times 12 \mathrm{~cm})$ as previously described. Ten and 27 covered plants were infested in the first and second assays, respectively, with ten whitefly adults (B-biotype). In all experiments, a similar number of covered but uninfested (without whiteflies) plants were used as controls. Whiteflies and cylinders were removed after $48 \mathrm{~h}$.

\section{Tomato response to aphids: aphid infestations}

One hour after whiteflies were removed in the first assay, two adult winged aphids (Sp clone) were placed on the upper-most fully expanded leaf of every preinfested or control plant. The plants were covered by plastic cylinders. The adults were removed after a $96 \mathrm{~h}$ period and only two nymphs were maintained on the leaves. Ten and 20 days later, the total numbers of adults and nymphs per plant were counted.

Similar methodology was followed in the second assay. We used a different aphid clone (Nt clone). The adults were removed after $24 \mathrm{~h}$ and all nymphs born during this period were kept on the same leaf. After 11 days, the numbers of adults and nymphs were counted and only two adult aphids were kept on the plant. Counting was repeated 11 days later (the same time interval as the pre-reproductive period).

The numbers of adult aphids and nymphs per treatment were $\log _{10}(x+1)$ or $\sqrt{x}$ transformed, then analyzed by a oneway ANOVA and means compared by the Tukey HSD or by the Mann-Whitney $U$ test for data not adjusted to a normal distribution (Statgraphics, 1997).

\section{Results}

\section{Response to B. tabaci induced by aphids}

The averaged total numbers of individuals of $B$. tabaci per plant 27 days after whitefly infestation were significantly $\left(F_{1.18}=6.72, P=0.02\right)$ lower on plants previously infested by $M$. euphorbiae than those observed on uninfested control plants when whiteflies infested the plants one hour after aphids were removed (fig. 1a). Moreover, differences between aphid-infested and control plants were significant for all three B. tabaci developmental stages: L3 $\left(F_{1.18}=5.51\right.$, $P=0.03)$, L4 $\left(F_{1.18}=7.86, P=0.01\right)$ and newly emerged adults $\left(F_{1.18}=5.64, P=0.03\right)$ (fig. 1a).

When infestation by $B$. tabaci occurred $18 \mathrm{~h}$ after aphids were eliminated from the plants, the total number of individuals $\left(F_{1.20}=13.24, P=0.00\right)$ and the averaged number of adults $\left(F_{1.20}=13.01, P=0.00\right)$ were significantly lower on preinfested than on control plants, but no significant differences in the numbers of L3 or L4 were detectable (fig. 1b). In contrast, no significant differences were detected between aphid-infested and control plants when whitefly infestation occurred four days after aphid removal (fig. 1c).

Moreover, control plants which had empty plastic cages hosted similar numbers of whiteflies to those plants without any aphid or cage on their leaves (data not shown). This indicates that using plastic cages to confine aphids in these assays did not affect subsequent whitefly infestation results.

\section{Systemic response to $\mathrm{B}$. tabaci induced by aphids}

In the 18-h assay with the whiteflies confined into clipcages, fewer adults $\left(F_{1.18}=6.56, P=0.02\right)$ and total whiteflies $\left(F_{1.18}=6.47, P=0.02\right)$ were counted on the upper leaf contiguous to the aphid-infested leaf of the preinfested 

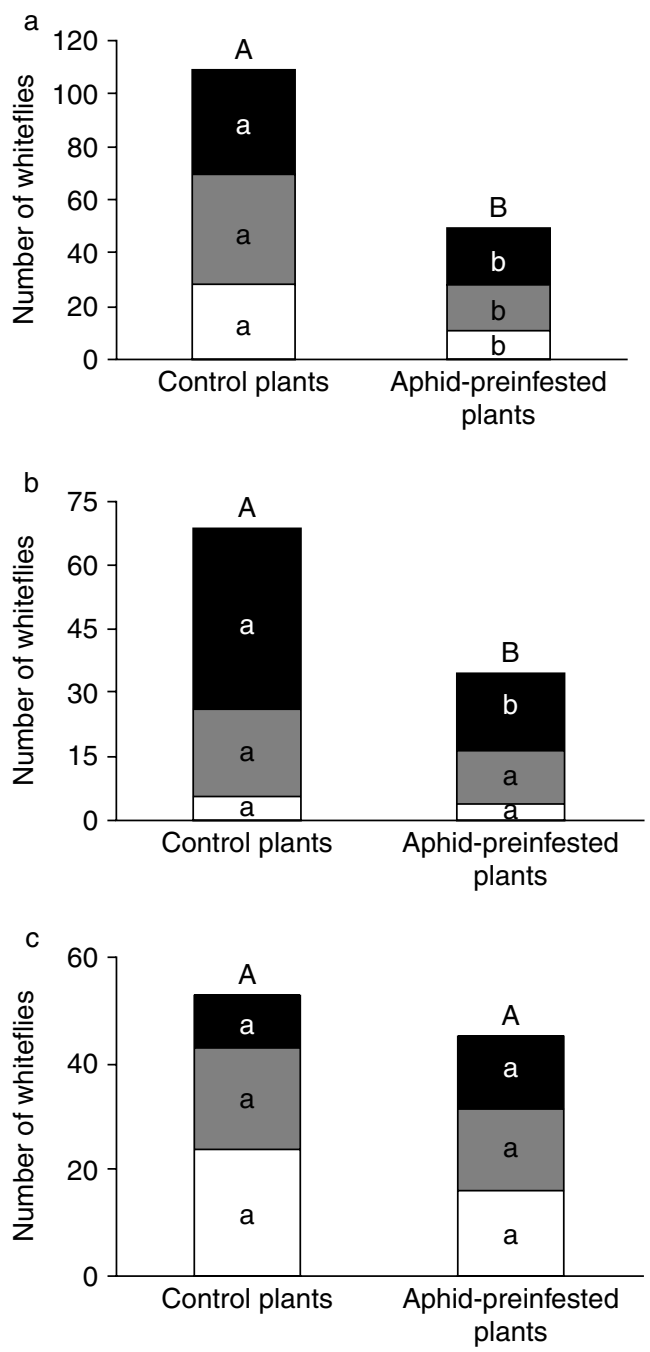

Fig. 1. Mean numbers of L3, L4 or adults (empty pupal cases) of B. tabaci (B-biotype) observed on the aphid-infested and control plants at 27 days after infestation with five female whiteflies. Aphids had been in contact with the plants for three days and were removed (a) one hour, (b) 18 hours or (c) four days prior to whitefly infestation. Lower case letters compare values for every life stage separately; capital letters compare the total numbers of whiteflies. Different letters on bars from the same graphic indicate significant $(P<0.05)$ differences by ANOVA $\left(\square, \mathrm{L}_{3}\right.$; $\square, \mathrm{L}_{4} ; \mathbf{\square}$, adults).

plants than those found on the corresponding upper leaf, contiguous to the non-infested leaf, of the control plants (fig. 2a).

In plants infested with B. tabaci $18 \mathrm{~h}$ after aphid removal, statistically significant differences in the averaged numbers of L3, L4, adult or total whiteflies were not detectable between the aphid-infested leaves and the uninfested contiguous leaves of the same plants (fig. $2 b$ ).

\section{Responses to M. euphorbiae induced by whiteflies}

In the first assay (aphid clone $\mathrm{Sp}$ ), the mean number of nymphs per plant (Nph 1 per $\mathrm{Pl}$ ) and per adult (Nph 1 per
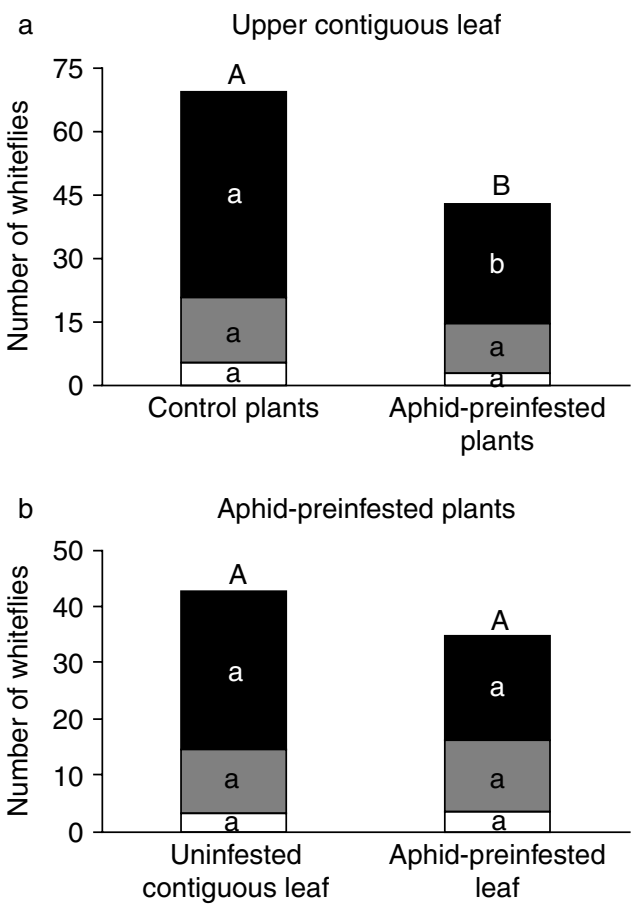

Fig. 2. Mean numbers of L3, L4 or adults of B. tabaci (B-biotype) observed at day 27 (a) on the leaf contiguous to the aphidinfested leaf of the aphid-infested plants or contiguous to the equivalent uninfested leaf of the control plants, and (b) on the aphid-infested and the uninfested contiguous leaves of plants previously infested by aphids. Aphids had been in contact with the plants for three days and were removed $18 \mathrm{~h}$ prior to whitefly infestation. Lower case letters compare values for every life stage separately; capital letters compare the total numbers of whiteflies. Different letters on bars indicate significant $(P<0.05)$ differences by ANOVA $\left(\square, \mathrm{L}_{3} ; \square, \mathrm{L}_{4} ; \boldsymbol{\square}\right.$, adults).

Ad 0) ten days after adult aphid removal were significantly higher than on uninfested control plants (fig. 3a). Twenty days after adult removal the differences between whitefly preinfested and uninfested plants disappeared (fig. 3a). On the contrary, in the second assay with aphid clon $\mathrm{Nt}$, no statistically significant differences were detected at any time point on the parameters analyzed (fig. $3 b$ ).

\section{Discussion}

\section{Induction of plant resistance to $\mathrm{B}$. tabaci by aphid feeding}

Results from the present work demonstrate that resistance to $B$. tabaci is induced in susceptible tomato plants after a previous infestation by the potato aphid M. euphorbiae. Three days of previous contact with 20 apterous-adult aphids were enough for the plants to acquire a certain level of resistance to the B biotype of B. tabaci. Similarly, Agrawal et al. (2000) observed that whitefly populations in cotton were directly and negatively affected by a previous infestation with approximately 30 Tetranychus turkestani spider mites. However, the present study is the first report (to our knowledge) where resistance to whiteflies induced by other insects has been demonstrated. Other studies have reported that feeding by aphids Myzus persicae, Aphis gossypii or 
a
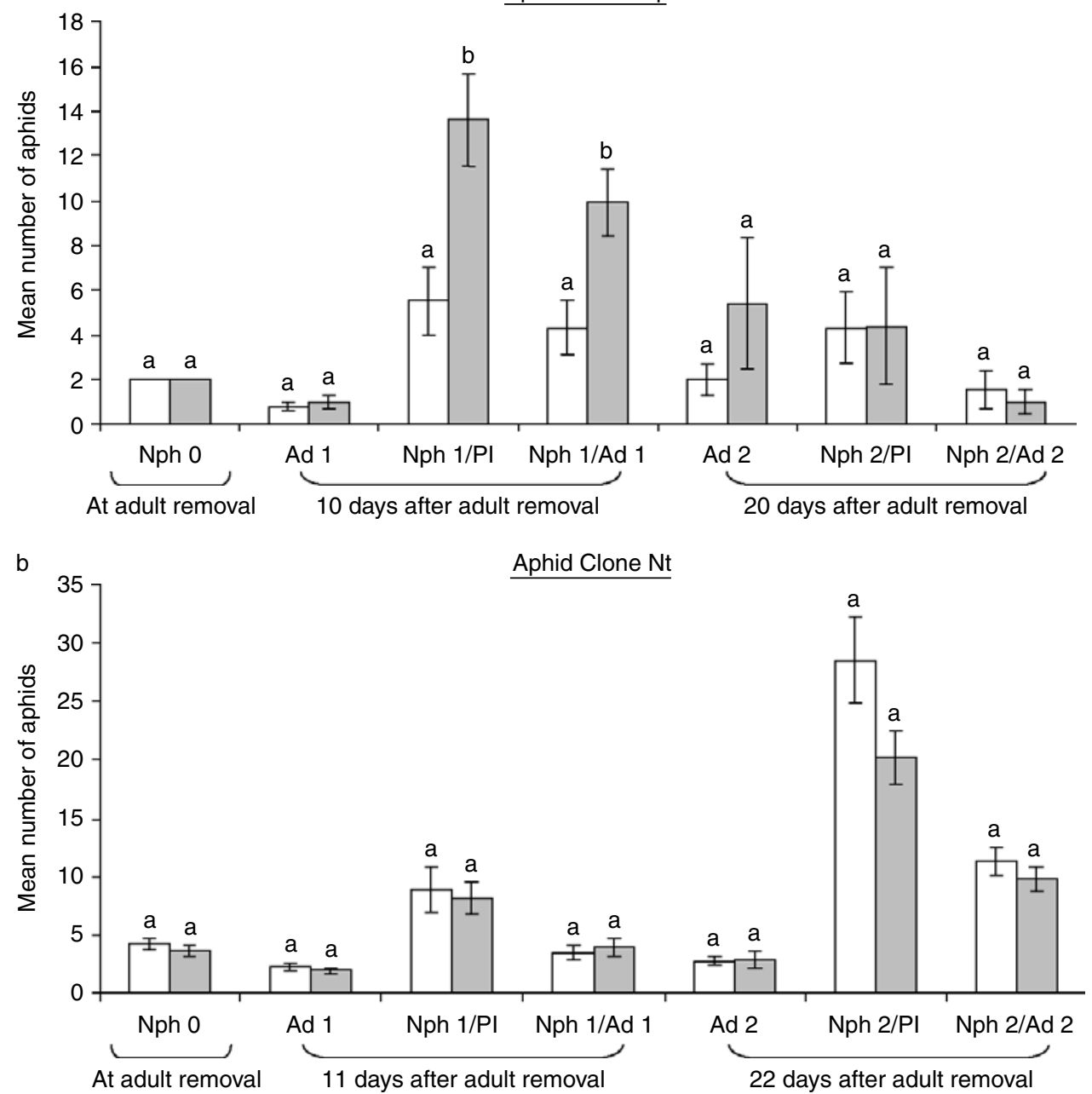

Fig. 3. Mean $( \pm S E)$ numbers of aphid nymphs and adults per plant and per adult with and without previous infestation with $B$. tabaci during $48 \mathrm{~h}$. Different letters on bars indicate significant $(P<0.05)$ differences by ANOVA or by the Mann-Whitney $U$ test for data not adjusted to a normal distribution. Nph 0, nymphs at the time point of adult removal; Ad 1 and Nph1, adults and nymphs, respectively, at ten or 11 days after adult removal; $\mathrm{Ad} 2$ and $\mathrm{Nph} 2$, adults and nymphs, respectively, at 20 or 22 days after adult removal; $\mathrm{Pl}$, plant ( $\square$, control plants; $\square$, whitefly preinfested plants).

Rhopalosiphum padi induced resistance to the same aphid species (Wool \& Hales, 1996; Quiroz et al., 1997; Messina et al., 2002; Sauge et al., 2002). In contrast to these effects, feeding by $R$. padi had limited effect on Diuraphis noxia, while a prior $D$. noxia infestation did not affect subsequent infestations by any of both aphid species (Messina et al., 2002). Furthermore, previous infestation of the susceptible peach cultivar GF305 slightly enhanced larviposition of $M$. persicae females (Sauge et al., 2002). Also, Stout et al. (1998) observed that the relative growth rates of chewing $S$. exigua larvae were $10-50 \%$ higher when fed on leaves preinfested with M. euphorbiae than when fed on control leaves. These variable results make plant responses to aphids a clear example of specificity of effect as defined by Karban \& Baldwin (1997).

It has been described that phloem-feeding insects induce a number of plant responses as a result of transcriptional reprogramming in their host plants (reviewed by Thompson \& Goggin, 2006), but the proximate mechanisms of induction of resistance to insects by aphid feeding remain unclear. Reduced reproductive performance of $A$. gossypii on cotton seedlings, which had survived to a previous infestation by the same aphid species, was identified as a result of cumulative plant damage and reduced nutritional quality after aphid feeding, rather than to the production of some chemicals in the plant (Wool \& Hales, 1996). However, the aphid-induced resistance to whiteflies observed in the present study cannot be easily attributable to direct plant damage because young seedlings were not tested, but onemonth old tomato plants. Moreover, aphid populations for the initial infestation were allowed to freely increase in size during more than 20 days on cotton seedlings; meanwhile, aphids in our assays stayed on the tomato plants for three days only. In accordance with our observations in the present study, it is currently agreed that aphid feeding causes limited direct plant damage (Zhu-Salzman et al., 2005) although Rabbinge et al. (1981) suggested that indirect 
damage due to the secretion of honeydew that eventually induces a reduction in stomatal conductance and photosynthesis rate can be serious.

In contrast to the above-mentioned effects on $B$. tabaci by aphids and spider mites, infestation of tomato by whitefly $B$. argentifolii (corresponding to the B-biotype of $B$. tabaci) was not affected by previous infestations with chewing insects, such as the vegetable leafminer Liriomyza trifolii or the corn earworm Helicoverpa zea (Inbar et al., 1999). Conversely, different behaviour (oviposition, feeding preference) and reduction of the survival rates and developmental times of these chewing insects were observed by the same authors in tomato plants previously infested by B. argentifolii. These results can be explained by differences in the feeding behaviour (sucking or chewing) of the first-infesting arthropods in these two sets of experiments. Phloem-feeding insects use their stylets to penetrate between the epidermal and parenchymal cells intercellularly to reach phloem sieve tubes. This results in limited plant damage that is distinct from that of chewing insects (Zhu-Salzman et al., 2005). It has been postulated that whiteflies and other phloem-feeders are not as sensitive as chewing insects to many plant defences because secondary metabolites or proteins are usually not expressed or available in the phloem (Mayer et al., 2002). Using the electrical penetration graph (EPG) technique (Tjallingii, 1988), our group had previously demonstrated that innate resistance to $B$. tabaci in tomato is due to factors in the epidermis and/or mesophyll that inhibit or delay the whiteflies from reaching phloem sieve elements (Jiang et al., 2001).

Similarly to the results shown in the present work, exogenous treatment of leaves with BTH induced local resistance to $B$. tabaci in tomato and cucumber (Correa et al., 2005; Nombela et al., 2005) and to M. euphorbiae in tomato (Cooper et al., 2004). Previous studies demonstrated that $M$. euphorbiae and $M$. persicae aphids are potent inducers of PR proteins, similarly to host responses observed with pathogens or salicylic acid (SA)/BTH treatment (Bostock et al., 2001). Both SA- and jasmonate (JA)-ethylene-dependent pathways have been demonstrated to be activated in tomato in response to feeding by M. euphorbiae (Walling, 2000; Martínez de Ilarduya et al., 2003).

Current results also indicate that resistance of tomato plants against B. tabaci was both local (LAR) and systemically (SAR) expressed. On the contrary, the expression of the resistance induced by treatment of tomato with BTH was limited to treated leaves (Nombela et al., 2005). Moreover, whitefly numbers in the present work were significantly reduced when infestation occurred between one and $18 \mathrm{~h}$ after aphid removal. However, reduction was not detectable when four days passed between aphid removal and whitefly infestation, which was equivalent to seven days after aphid infestation as these insects fed on the plants for three days. So, whitefly resistance was transiently induced by M. euphorbiae. This effect was even shorter lasting than the previously observed resistant response to $B$. tabaci locally induced in tomato plants by BTH, which did not last longer than ten or 11 days after treatment (Nombela et al., 2005). Plant responses to aphid feeding are rapid (Smith \& Boyko, 2006). M. persicae feeding induces resistance responses in foliage of apple (Malus) within as little as two hours, which persist as long as $48 \mathrm{~h}$ (Kfoury \& Masonie, 1995; Sauge et al., 2002). It has been demonstrated that levels of $P R-1$ and $G l u B$ transcripts in susceptible tomato plants significantly decrease one week after potato aphid infestation, but systemic accumulation of transcripts from any of these PR-genes in adjacent non-infested leaflets of the same plant was not detected (Martínez de Ilarduya et al., 2003). For this reason, it is unlikely that these defence-response genes should be the best candidates to entirely explain the systemic resistance against $B$. tabaci induced by aphids in susceptible tomato in the current work.

\section{Variable plant responses to $\mathrm{M}$. euphorbiae induced by B. tabaci}

The responses to $M$. euphorbiae of the plants previously infested by whiteflies were shown to be dependent on the aphid clone tested. Sp-clone adults, obtained ten days after adult removal, on tomato plants preinfested with whiteflies, produced a significantly higher number of nymphs than those on uninfested control plants. However, we did not observe significant differences when the aphid clone $\mathrm{Nt}$ was used. These results indicate that changes in plant properties provoked by a previous infestation by whitefly are probably beneficial to clone $\mathrm{Sp}$ of $M$. euphorbiae. This confirms that feeding by similar insects can produce changes in plant quality (Walling, 2000; Messina et al., 2002), improving the development of other species. A positive effect on aphids was previously observed by other authors. Aphis fabae has beneficial effects when living in colonies (Prado \& Tjallingii, 1997). These authors observed that some changes during stylet route towards the phloem can be considered as increased host plant acceptance. Sauge et al. (2002) observed that a previous infestation with $M$. persicae in susceptible peach increases larviposition by adult aphid females. Dugravot et al. (2007) evaluated the influence of previous infestation by conspecific $M$. persicae and heterospecific M. euphorbiae on $M$. persicae feeding activities on potato plants. They observed that the effects of previous infestation occurring at the local level were opposite to those observed at the systemic level. M. persicae food acceptance was slightly enhanced on previously infested leaves, whereas it was inhibited on no-infested leaves of infested potato plants.

The variability of tomato response induced by whitefly feeding depending on the aphid clone tested presents a certain parallelism with the isolate-specific innate resistance to aphids mediated by the $M i-1$ gene; this tomato gene conferred resistance to a red isolate of M. euphorbiae but had no effect on a green isolate of the same species (Rossi et al., 1998). Similarly, plants carrying the $M i-1$ gene were resistant to $M$. euphorbiae isolates from France and The Netherlands, were susceptible to two isolates from California, one from New Jersey and one from North Carolina, with mixed results against two other isolates from California and no effect on two isolates of M. persicae (Goggin et al., 2001). These authors postulated that this great variability (which is independent of geographical origin, aphid colour or original host) could be due to the presence of certain virulence or avirulence factors in the different aphid isolates. Whether B. tabaci feeding induces, in the Mi-lacking plants, a compound that mimics the recognition of the virulence or avirulence factor from the aphid clone is a stimulating hypothesis, which is not possible to be confirmed until the above-mentioned virulence or avirulence factors can be identified. Moreover, clear interclonal variation in the aphid performance was observed in the present work. The adult aphids of Sp clone were left $96 \mathrm{~h}$ on the tomato plant to obtain enough number of nymphs, but only $24 \mathrm{~h}$ was enough for the $\mathrm{Nt}$-clone in 
order to reach the same purpose. Also, the number of aphids in the control plants was consistently different between the both aphid clones. The interclonal variation in aphid performance has been observed by other authors. De Barro et al. (1995) provided evidence of genetic variation in performance on host and evidence for clonal adaptation to particular host species. Goundoudaki et al. (2003) proposed that the interclonal variation in performance is possibly related to the colour of $M$. persicae. The genetic variability of aphid clones suggests that the evaluation of induced or constitutive resistance should be based on data obtained from more that one aphid clone.

It was also observed in our study that the duration of tomato response to a previous infestation by $B$. tabaci is apparently limited; within ten days, the reproduction (mean number of nymphs) of $M$. euphorbiae increased significantly when tomato plants had been previously infested by B. tabaci. However, after 20 days, these differences were not observed. Similarly to the resistance to $B$. tabaci, induced by aphid preinfestation, the increased susceptibility to the Spclone aphids was transiently induced by the whiteflies. Other transient plant responses to aphids have been induced by external biotic or abiotic agents (Sauge et al., 2002; Cooper et al., 2004).

\section{Asymmetry in the induced responses to/by piercing-sucking insects}

The interaction between the two piercing-sucking insect species of this work was asymmetric because aphid feeding induced plant resistance to $B$. tabaci; meanwhile, preinfestation by whiteflies induced variable tomato responses against M. euphorbiae, depending on the aphid clone tested. Asymmetrical interactions between insects are not uncommon; whitefly feeding induced behavioural differences (oviposition, feeding preferences) and reduced survival rates and development times of cabbage looper (Trichoplusia ni) and leaf miner (Liromyza trifolii). Meanwhile, previous exposition to leaf miners had little or no effect on silverleaf whitefly oviposition (Mayer et al., 2002). The asymmetrical interactions between whiteflies and aphids observed in the present study are likely due to different salivary components that may elicit different responses from their host. The general and species-specific elicitors may correspond to one of the known salivary constituents or may be an uncharacterized component of the saliva (Walling, 2000). Moreover, the general and species-specific elicitors may be directly synthesized by the insect or may be a product of endosymbiotic bacteria (Costa et al., 1995; Douglas, 1998).

In addition, whitefly and aphid populations sometimes display different behaviours in response to the same external factor affecting the host plant. So, feeding by spider mite T. turkestani in cotton plants, which induced resistance to $B$. tabaci, had a positive effect on populations of $M$. persicae (Agrawal et al., 2000). The key to understand such asymmetric interactions probably lies on the assumption that plant resistance to phloem-feeding insects is mediated by two types of plant genes; it is known that plant genes participating in the recognition of aphid herbivory act in concert with other plant genes involved in defence against herbivores. It has been proved that similarities exist in the types of plant genes expressed in response to feeding by different species of aphids. However, numerous differences in plant signalling and defence responses unique to specific aphid-plant interactions have been identified (Smith \& Boyko, 2006).

The complexity of the understanding of induced plant responses to herbivory needs to be addressed using both holistic and mechanistic approaches (Agrawal, 2005). The present study tried to take into account both types of approaches, as multi-species interactions in highly controlled environments were considered.

\section{Acknowledgements}

This research was partially funded by a CICYT Project (AGL2000-1591-C02-01). G. Nombela was financially supported by a contract I3-P2001-1 from the 'Programa de Incorporación de Investigadores' CSIC-FSE, Spain, and by another contract from the 'Programa Ramón y Cajal 2003' of the MCyT, Spain. E. Garzo was financially supported by a fellowship I3P-BPG2001 from the program 'Postgrado para formación y especialización en líneas de investigación de interés para el sector industrial' CSIC-FSE, Spain. Authors wish to thank Prof. Tjallingii for providing the Nt aphid clone.

\section{References}

Agrawal, A. (2005) Future directions in the study of induced plant responses to herbivory. Entomologia Experimentalis et Applicata 115, 97-105.

Agrawal, A., Tuzun, S. \& Bent, E. (1999) Induced Plant Defenses against Pathogens and Herbivores. 390 pp. St. Paul, Minnesota, APS Press.

Agrawal, A., Karban, R. \& Colfer, R.G. (2000) How leaf domatia and induced plant resistance affect herbivores, natural enemies and plant performance. Oikos 89, 70-80.

Bostock, R.M., Karban, R., Thaler, J.S., Weyman, P.D. \& Gilchrist, D. (2001) Signal interactions in induced resistance to pathogens and insect herbivores. European Journal of Plant Pathology 107, 103-111.

Cooper, W.C., Jia, L. \& Goggin, F.L. (2004) Acquired and R-gene-mediated resistance against the potato aphid in tomato. Journal of Chemical Ecology 30, 2527-2542.

Correa, R.S.B., Moraes, J.C., Auad, A.M. \& Carvalho, G.A. (2005) Silicon and acibenzolar-S-methyl as resistance inducers in cucumber, against the whitefly Bemisia tabaci (Gennadius) (Hemiptera: Aleyrodidae) biotype B. Neotropical Entomology 34, 429-433.

Costa, H.S., Westcot, D.M., Ullman, D.E., Rosell, R., Brown, J.K. \& Johnson, M.W. (1995) Morphological variation in Bemisia endosymbionts. Protoplasma 189, 194-202.

De Barro, P.J., Sherratt, T.N., David, O. \& Maclean, N. (1995) An investigation of the differential performance of clone of the aphid Sitobion avenae on two host species. Oecologia 104, 379-385.

Douglas, A.E. (1998) Nutritional interactions in insect-microbial symbioses: Aphids and their symbiotic bacteria Buchnera. Annual Review of Entomology 43, 17-37.

Dugravot, S., Brunissen, L., Létocart, E., Tjallingii, W.F., Vicent, C., Giordanengo, P. \& Cherqui, A. (2007) Local and systemic responses induced by aphids in Solanum tuberosum plants. Entomologia Experimentalis et Applicata 123, 271-277.

Engelberth, J., Alborn, H.T., Schmelz, E.A. \& Tumlinson, J.H. (2004) Airborne signals prime plants against insect 
herbivore attack. Proceedings of the National Academy of Sciences USA 101, 1781-1785.

Fereres, A., Lister, R.M., Araya, J.E. \& Foster, J.E. (1989) Development and reproduction of the English grain aphid (Homoptera: Aphididae) on wheat cultivars infected with Barley Yellow Dwarf Virus. Environmental Entomology 18, 388-393.

Goggin, F.L., Williamson, V.M. \& Ullman, D.E. (2001) Variability in the response of Macrosiphum euphorbiae and Myzus persicae (Hemiptera: Aphididae) to the tomato resistance gene Mi. Environmental Entomology 30, 101-106.

Goundoudaki, S., Tsitsipis, J.A., Margaritopoulos, J.T., Zarpas, K.D. \& Divanidis, S. (2003) Performance of the tobacco aphid Myzus persicae (Hemiptera: Aphididae) on Oriental and Virginia tobacco varieties. Agricultural and Forest Entomology 5, 285-291.

Hammerschmidt, R., Métraux, J.P. \& van Loon, L.C. (2001) Inducing resistance: a summary of papers presented at the First International Symposium on Induced Resistance to Plant Diseases, Corfu, May 2000. European Journal of Plant Pathology 107, 1-6.

Heil, M. \& Kost, C. (2006) Priming of indirect defences. Ecological Letters 9, 813-817.

Hunter, M.D. (2000) Mixed signals and cross-talk: interactions between plants, insect herbivores and plant pathogens. Agricultural and Forest Entomology 2, 155-160.

Hunter, M.D. (2002) A breath of fresh-air: beyond laboratory studies of plant volatile-natural enemy interactions. Agricultural and Forest Entomology 4, 81-86.

Inbar, M., Doostdar, H., Leibee, G.L. \& Mayer, R.T. (1999) The role of plant rapidly induced responses in asymmetric interspecific interactions among insect herbivores. Journal of Chemical Ecology 25, 1961-1979.

Jiang, Y.X., Nombela, G. \& Muñiz, M. (2001) Analysis by DC-EPG of the resistance to Bemisia tabaci on an Mitomato line. Entomologia Experimentalis et Applicatta 99, 295-302.

Karban, R. \& Baldwin, I.T. (1997) Induced Responses to Herbivory. 319 pp. University of Chicago Press, Chicago, IL, USA.

Karban, R., Agrawal, A.A., Thaler, J.S. \& Adler, L.S. (1999) Induced plant responses and information content about risk of herbivory. Tree 14, 443-447.

Kfoury, L. \& Masonie, G. (1995) Characteristics of the resistance of the peach cultivar Rubira to Myzus persicae Sulzer. Agronomie 15, 277-284.

Kunz, W., Schurter, R. \& Maetzke, T. (1997) The chemistry of benzothiadiazole plant activators. Pesticide Science 50, 275282.

Martínez de Ilarduya, O., Xie, Q. \& Kaloshian, I. (2003) Aphidinduced defense responses in Mi-1-mediated compatible and incompatible tomato interactions. Molecular Plant Microbe Interactions 16, 699-708.

Mayer, R.T., Inbar, M., Mckenzie, C.L., Shatters, R., Borowicz, V., Albrecht, U., Powell, C.A. \& Doostdar, H. (2002) Multitrophic interactions of the silverleaf whitefly, host plants, competing herbivores, and pathogens. Archives of Insect Biochemistry and Physiology 51, 151-169.

Messina, F.J., Taylor, R. \& Karren, M.E. (2002) Divergent responses of two cereal aphids to previous infestation of their host plant. Entomologia Experimentalis et Applicata 16, 43-50.

Muñiz, M. \& Nombela, G. (2001) Bemisia tabaci: A new clip-cage for biological studies. European Whitefly Studies Network A2, $1-2$.
Murugan, M. \& Dhandapani, N. (2006) Induced systemic resistance activates defense responses to interspecific insect infestations on tomato. Journal of Vegetable Science 12, 43-62.

Nombela, G., Williamson, V.M. \& Muñiz, M. (2003) The rootknot nematode resistance gene $M i-1.2$ of tomato is responsible for resistance against the whitefly Bemisia tabaci. Molecular Plant-Microbe Interactions 16, 645-649.

Nombela, G., Pascual, S., Aviles, M., Guillard, E. \& Muñiz, M. (2005) Benzothiadiazole (BTH) induces local resistance to Bemisia tabaci in tomato plants. Journal of Economic Entomology 98, 2266-2271.

Oostendorp, M., Kunz, W., Dietrich, B. \& Staub, T. (2001) Induced resistance in plants by chemicals. European Journal of Plant Pathology 107, 19-28.

Prado, E. \& Tjallingii, W.F. (1997) Effects of previous plant infestation on sieve element acceptance by two aphids. Entomologia Experimentalis et Applicatta 82, 189-200.

Quiroz, A., Petterson, J., Pickett, J.A., Wadhams, L.J. \& Niemeyer, H.M. (1997) Semiochemicals mediating spacing behavior of bird cherry-oat aphid, Rhopalosiphum padi feeding on cereals. Journal of Chemical Ecology 23, 2599-2607.

Rabbinge, R., Drees, E.M., van Der Graaf, M., Verberne, F.C.M. \& Wesselo, A. (1981) Damage effects of cereal aphids in wheat. Netherland Journal of Plant Pathology 87, 217-232.

Roberts, P.A. \& Thomason, I.J. (1986) Variability in reproduction of isolates of Meloidogyne incognita and M. javanica on resistant tomato genotypes. Plant Disease 70, 547-551.

Rodríguez-Saona, C., Crafts-Brandner, S.J. \& Cañas, L.A. (2003) Volatile emissions triggered by multiple herbivore damage: beet armyworm and whitefly feeding on cotton plants. Journal of Chemical Ecology 29, 2539-2550.

Rossi, M., Goggin, F.L., Milligan, S.B., Kaloshian, I., Ullman, D.E. \& Williamson, V.M. (1998) The nematode resistance gene $\mathrm{Mi}$ of tomato confers resistance against the potato aphid. Proceedings of the National Academy of Sciences of the United States of America 95, 9750-9754.

Sauge, M.H., Lacroze, J.P., Poëssel, J.L., Pascal, T. \& Kervella, J. (2002) Induced resistance by Myzus persicae in the peach cultivar 'Rubira'. Entomologia Experimentalis et Applicata 102, 29-37.

Siddiqui, I.A. \& Shaukat, S.S. (2004) Systemic resistance in tomato induced by biocontrol bacteria against the rootknot nematode, Meloidogyne javanica is independent of salicylic acid production. Journal of Phytopathology 152, 48-54.

Smith, C.M. \& Boyko, E.V. (2006) The molecular bases of plant resistance and defense responses to aphid feeding: current status. Entomologia Experimentalis et Applicata 122, 1-16.

Smith-Becker, J., Keen, N.T. \& Becker, J.O. (2003) AcibenzolarS-metyl induces resistance to Colletotrichum lagenarium and cucumber mosaic virus in cantaloupe. Crop Protection 22, 769-774.

Statgraphics (1997) Statgraphics Plus for Windows 3.1. Statistical Graphics Corp.

Stout, M.J., Workman, K.V., Bostock, R.M. \& Duffey, S.S. (1998) Specificity of induced resistance in the tomato, Lycopersicon esculentum. Oecologia 113, 74-81.

Thaler, J.S., Stout, M.J., Karban, R. \& Duffey, S.S. (2001) Jasmonate-mediated induced plant resistance affects a community of herbivores. Ecological Entomology 26, 312-324.

Thompson, G.A. \& Goggin, F.L. (2006) Transcriptomics and functional genomics of plant defence induction by phloem-feeding insects. Journal of Experimental Botany 57, $755-766$. 
Tjallingii, W.F. (1988) Electrical recording of stylet penetration activities. pp. 95-108 in Minks, A.K. \& Harrewijn, P. (Eds) Aphids, Their Biology, Natural Enemies and Control, Vol. 2B. Amsterdam, Elsevier.

Walling, L. (2000) The myriad plant responses to herbivores. Journal of Plant Growth Regulation 19, 195-216.
Wool, D. \& Hales, D.F. (1996) Previous infestation affects recolonization of cotton by Aphis gossypii: induced resistance or plant damage? Phytoparasitica 24, 39-48.

Zhu-Salzman, K., Bi, J.L. \& Liu, T.X. (2005) Molecular strategies of plant defense and insect counter-defense. Insect Science 12, 3-15. 